DOI No: http://dx.doi.org/10.29228/Joh40068

Makale Türü: Araştırma makalesi

Geliş Tarihi: 08.11.2019

Yayın Tarihi: 31.12.2019
Article Type: Research article

Submitted: 08.11.2019

Publishing date: 31.12 .2019

Atıf Bilgisi / Reference Information

Karataş, H. (2019), Tantrik ve Ezoterik Dini Geleneklerde Mandala. Journal of

History School, 43, 1768-1786.

\title{
TANTRIK VE EZOTERIK DINI GELENEKLERDE MANDALA Hüsamettin KARATAŞ*
}

\section{$\ddot{O} z$}

Mandalalar, Hint ve Doğu kökenli dinlerde, özellikle de gizemli inançları ön plana çıkaran ve daha çok Tantrik ve Esoterik dini uygulamaları ve anlayışları savunan gruplar tarafından kullanılan dua veya tapınım çarklarıdır. Mandaralar, bu din veya dini gruplarda tapınmak yahut yüce varlıklardan bazı taleplerde bulunmak maksadıyla kullanıldığından, inancın ve ibadetin en kutsal değerlerinin temsili sayılmaktadır. ${ }^{1}$ Mandalalar genellikle daire ya da köşeli bir düzlem üzerine, harf, şekil, resim veya bazı özel işaretlemelerle oluşturulmuş tablolardır. Çoğunlukla daire, kare veya dikey dikdörtgen şekillerin tercih edildiği bu tablolar, kutsalı sembolize eden figürleri içerdiğinden dolayı tapınılacak objeler olarak görülmektedir. Bazı toplumlarda mandala, kutsalla ilişkili olarak farklı anlamlarda da kullanılabilmektedir.

Anahtar Kelimeler: Mandala, Tantrik, Ezoterik, Din, Dini Sembol, Tapınma, Mantra, Kutsal, Ritüel, Dua Çarkı

\section{Mandala in Tantric and Esoteric Religious Traditions}

\begin{abstract}
Mandalas are prayer or worship wheels used in groups of Indian and Eastern religions, particularly those that promote mysterious beliefs and advocate Tantric and Esoteric religious practices and understandings. Mandalas are regarded as representations of the most sacred values of faith and worship, as they are used to worship these religious or religious groups or to make certain demands from the supreme beings. Mandalas are

* Dr. Öğretim Üyesi, Frrat Üniversitesi İlahiyat Fakültes, Felsefe ve Din Bilimleri, Dinler Tarihi Anabilim Dalı, Elazığ, Türkiye, hkaratash@ firat.edu.tr. orcid: 0000-0002-3285-8517
\end{abstract}


usually tables created on a circle or square plane with letters, shapes, pictures, or some special markings. These paintings, which mostly prefer circle, square or vertical rectangular shapes, are seen as objects to be worshiped because they contain figures symbolizing the holy. In some societies, the term mandala may be used in different meanings in relation to the sacred.

Keywords: Mandalas, Tantric Buddhism, Esoteric, Religious Symbol, Worship, Mantras, Sacred, Ritual, Prayer Wheel.

\section{GİRiş}

Kadim dinlere beşiklik etmiş Hint coğrafyası konumu itibariyle kuzeyinde bir set şeklinde Himalaya sıradağları, güneyinde Atlas okyanusu, doğusunda Bengal körfezi ve batısında da Umman denizi olan bir yarımadadır. Hindistan'ın fiziki yapısı onu dünyadan biraz uzaklaştırıp yabancı istilasından korumuştur. $\mathrm{Bu}$ durum Hindistan'da kendine has bir dini yapının oluşmasını ve bu yapının da uzun yıllar korunmasını sağlamıştır. ${ }^{2}$

Hint coğrafyasının biline ilk dini geleneği Hinduizm'dir. Bunun dişında Budizm, Caynizm ve ve Sihizm'de bu coğrafyada ortaya çıkıp gelişmiştir. Bu açıdan köken olarak Hint coğrafyasında ortaya çıktıklarından dolayı bu dinler için Hint kökenli dinler ifadesi kullanılmaktadır. ${ }^{3}$ Hint kökenli dinlerin bazı ortak yönlerinin olduğu bilinmektedir. $\mathrm{Bu}$ ortak noktalardan biri de bireyin nihai kurtuluşa ulaşmasına yardımcı olan yoga, meditasyon ve bu ritüelleri gerçekleştirirken kullanılan yöntemlerdir. Bu yöntem ve tekniklerden biri de mandala anlayışı ve uygulamalarıdır. ${ }^{4}$ Hint kökenli dinlerde meditasyon esnasında odaklanmak için mandala objeleri kullanılır. Hinduizm'de doğru bir şekilde meditasyon ve yoga yapmanın kurallarından bir tanesi duygulardan arınıp, zihni dış etkilerden korumak için dikkati meditasyon objesine yöneltmektir. Budizm'de de bu durum Hinduizm'le paralellik gösterir. ${ }^{5}$

\footnotetext{
${ }^{2}$ Ali İhsan Yitik, Doğu Dinleri, , Ankara 2014, s.21.

${ }^{3}$ Ali İhsan Yitik, Hint Kökenli Dinlerde Karma İnancının Tenasüh İnancıyla İlişkisi, İstanbul 1996, s. 17

${ }^{4}$ Yitik, Hint Kökenli Dinlerde Karma İnancının Tenasüh İnanclyla İlişkisi, s.39.

${ }^{5}$ James Hewitt, Meditasyon (çev. Rezan Süer),., İstanbul 2000, s.10-12.
} 


\section{1- Tantrik ve Ezoterik Dini Gelenlerde Mandala Anlayışı}

Mandalalar genellikle tantrik ${ }^{6}$ ve ezoterik ${ }^{7}$ eğilimli dini gruplar tarafindan kullanılmaktadır. Ancak mandala kullanımını ve etkinlik alanını dikkate aldığımızda sadece tantrik ve ezoterik gruplarla sınırlanamayacak kadar geniş olduğunu söylemek mümkündür. Mandala anlayışını veya mandala öğretisini benimseyenler için o, temelde kutsallığın içkin dinamiklerine ve onlardaki gizli güçlerin potansiyel etkilerine işaret sayılmaktadır. Dolayısıyla mandalalar mutlak kurtuluşa ulaşmanın en doğru yöntemlerinden biri olarak kabul edilmektedir.

Tantrizim, Hint ve doğu kökenli dini geleneklerde batini uygulamaları konu alan çok sayıda metnin ortak adıdır. Örneğin Budist tantralarının kökeni, 7. yüzyıldan önceye dayanır. Tantra aydınlanmaya süratle ulaşmak için uygulanan özel yoga ile ilgili metotlar ve kullanılan kitaplar serisini ifade eden faaliyetle ilgili bir terimdir. Tantrizm, verimsiz çilelerle bağımsızlığın kazanılamayacağını, arzu ve isteklerden kurtulmanın yolunun tutkuları yok etmek yerine onları doyurmak olabileceğini savunan öğretidir. ${ }^{8}$

Ezoterizm ise herkese açıklanmayan ve öğretilmeyen saklı bilgi, sır manalarına gelir. Asıl gerçeklerin yalnızca anlayabilecek yetenek ve bilgide olanlara bildirilebileceği görüşü üzerine temellenen bir öğreti sistemidir. Mandala, Hint kökenli dinlerin dini geleneklerinde tantrik unsurlarla ilişkilendirilmiştir. Mandala, Hindistan, Tibet ve Çin'de gelişmekle birlikte daha sonra güçlü ezoterik unsurları bünyesinde barındıran Vajrayana'nın ${ }^{9}$ etkisiyle Japonya'ya geçmiş olup Hinduist ve Budist Tantrizm'i çerçevesinde daha da gelişmiştir. ${ }^{10}$ Tantrik dini gelenekler, kavramsal düşünceden daha derin bilinç seviyeleri üreten dinamik bir zihin kontrolüne ihtiyaç duymaktadır. Bu nedenle derin bilinç seviyeleri üretmek için bir takım semboller kullanmak zorunlu hale gelmektedir. Sembolik ritüel araçları düşünceyi belirli bir yöne kanalize ederek ritüellerdeki nihai amaca ulaşmaya yardımcı olmaktadır. Bu bağlamda Tibet

\footnotetext{
${ }^{6}$ Tantrik: Hint dinlerinde, batini uygulamaları konu alan yaklaşım.

${ }^{7}$ Ezoterik: Gizli öğreti, sır.

${ }^{8}$ L. R. Chawdhri, Practicals Of Mantras And Tantras, Sagar Publication, New Delhi 1985, s1620.

${ }^{9}$ Genelde kabul gören anlayışa göre, Budist okullar üç büyük gelenek altında toplanır: "Hinayana" (Küçük Araç), "Mahayana" (Büyük Araç) ve Vajrayana'dır. Vajrayana (Elmas Araç) aslında Mahayana'nın bir uzantısıdır. Batıda çoğunlukla sadece Tibet Budizmi veya Lamaizm olarak adlandırılır. Hâlbuki Vajrayana gerçekte Tibet'in dışında Japonya, Çin ve Moğolistan'da da yayılmış farklı okulların ortak tanımıdır. Vajrayana, Mahayana'nın felsefi temellerinden yola çıkar ve "uyanışa" giden yolu hızlandıran tantrik teknikleri benimser.

${ }^{10}$ E. Dale Saunders, The Encyclopedia of Religion, Macmillann Publishing Company, Newyork 1987, s. 156
} 
Budizmi'nde sembolik ritüel aracı olarak maṇala objeleri kullanılmaktadır. Mandala objeleri sayesinde birey, derin düşünme eylemi olan tefekkür için zihnini hazırlamış olmaktadır. Bu amaçla çeşitli şekil ve içeriklerden müteşekkil mandala objelerine odaklanarak ritüel gerçekleştirilir. ${ }^{11}$

Tantrizm, temel Hint dinleri olarak tanımlayabileceğimiz Hinduizm, Budizm ve Caynizm'de yaygın olarak kullanılan ezoterik bir adanmışlık geleneğidir. Bu bağlamda tantrizm genel olarak bireyi meditasyon sirasında mantra ${ }^{12}$, mudra ${ }^{13}$ ve mandala gibi uygulamalarla belirli obje ve nesnelere odaklayarak kurtuluşa ulaştırmayı hedeflemektedir. ${ }^{14}$ Mandalalar Hint dini geleneğinde gizemli inançları ön plana çıkarmak için kullanılmaktadır. Özellikle tantrik ve ezoterik inançları savunan gruplar tarafından tapınmak, tapınılan yüce varlıktan talepte bulunmak, meditasyon yapmak ve dua etmek amaciyla kullanılmaktadır. ${ }^{15}$ Mandalalar genellikle daire ya da köşeli bir düzlem üzerine, harf, şekil, resim veya bazı özel işaretlemelerle oluşturulmuş tablolardır. Çoğunlukla daire, kare veya dikey dikdörtgen şekillerin tercih edildiği bu tablolar, kutsalı sembolize eden figürleri içerdiğinden dolayı tapınılacak objeler olarak görülmektedir. ${ }^{16}$ Mandalaları ortak özelliği, çok sayıda değişkene sahip geometrik bir diyagram şeklini alan düzenler olmasıdır. Mandala bir merkeze bir eksene ve yön başlıklarına sahiptir. İlahi bir evreni tasvir ettiği için kozmogram olarak da adlandirilır. ${ }^{17}$

${ }^{11}$ John Blofeld, The Tantric Mysticism Of Tibet, Penguin Group Published, Arkana 1992, s.56.

${ }^{12}$ Mantra genellikle Sanskritce olan dini hece veya şiirdir. Kullanımı mantra ile ilişkili okul ve felsefesine göre değişiklik gösterir. Esasen ruhani kanallar olarak kullanılırlar, kelimeler ve oluşan titreşimlerden faydalanarak kişinin daha yüksek bir bilince ulaşmasını amaçlar.

${ }^{13}$ Mudra, Sanskritcede mühür ya da işaret demektir. Hinduizm ve Budizm pratiklerinde nefes ile birlikte kullanılırlar.

${ }^{14}$ Sonit, Bafna, "On the Idea of the Mandala as a Governing Device in Indian Architectural Tradition", Journal of the Society of Architectural Historians, Vol. 59, No. 1 (Mart, 2000), s.32.

${ }^{15}$ Karataş, Nichiren Budizmi, s.125-126.

${ }^{16}$ Karataş, Nichiren Budizmi, (Budizm'deki mandaralar, özellikle esoterik eğilimli yaklaşımlarda, kutsallığın içkin dinamiklerine ve onlardaki gizli güçlerin potansiyel etkilerine işaret sayıldığından, mutlak kurtuluşa ulaşmanın en doğru yöntemlerinden biri olarak görülmektedir. $\mathrm{Bu}$ dinde mandaralar özellikle esoterik eğilimli ekollerde yaygın olmakla birlikte, diğer gruplar tarafından da kullanılmaktadır. Kaynaklarda Japon Budizm'i içerisinde özellikle "Heian" ve "Kamakura" dönemlerinde söz konusu olan mandara (mandala) anlayışının yoğun olarak görüldüğüne işaret edilmektedir. Dolayısıyla Kamakura döneminin en önemli ekolleri arasında kabul edilen Nichirenci Budist hareketin de bu bağlamdaki gelişmelerden etkilenmiş olduğuna değinilmektedir). (Daha geniş bilgi için Bkz. Dictionary of Buddhism, 390-391; E. K. Neumaier, The Soverign All-Creating Mind The Motherly Buddha, s. 153).

${ }^{17}$ E. Dale Saunders, The Encyclopedia of Religion, Macmillann Publishing Company, Newyork 1987, Vol. 9, s.155 


\section{2- Mandala Nedir?}

Mandalanın anlamı oldukça geniştir. Bunlardan birkaçını burada ifade etmek konumuzun daha iyi anlaşılması açısında yararlı olacaktır. Çünkü mandalanın geniş anlam yelpazesi içerisinde her isteyen sadece kendi istediği tarafinı kullanmakta ve bu durum bazen bilmeden çoğu zaman kasten yanlış anlaşılmalara ya da yanlıș amaçlara hizmet edebilmektedir. Bizim asıl gayemiz konuyu bütün yönleriyle ve bilimsel objektiflik kriterlerine uygun bir şeklide aktarmak ve okuyucunun değerlendirmesine bırakmaktır. Mandala, Sanskritçe bir kelimedir. Mandala, "manda" ve "la"sözcüklerinin bir araya gelmesiyle oluşmuş bir kelimedir. Bu çerçevede "Manda"; öz, gerçek, asıl, enerji, kuvvet gibi anlamlara gelir. "La" ise; kab veya kap, el koymak, yakalamak, kaplamak, alan, demektir. Her ikisinin birleşmesinden oluşan "mandala" kelimesini "gerçek enerjinin alanı"(daha ziyade kare ya da daire şeklinde tasavvur edilir) ya da "asıl kuvvetin kabı"olarak ifade etmek (çevirmek) mümkündür. ${ }^{18}$ Terim anlamı açısından mandala, doğaüstü güçlere sahip varlıkların ve onlarla ilgili bütün gizemli hakikatlerin yer aldığı temsili gösterge demektir. Bu temsili göstergeler için hazırlanmış olan grafiklere veya şekilsel nesnelere mandara (mandala) tabloları veya dua çarkları ismi verilmektedir. ${ }^{19}$

Sanskritçe kullanımı içinde mandala terimi çok anlamlı, yani polisemiktir. $\mathrm{Bu}$ bağlamda mandala; daire, dairesel, yuvarlak, küre, halka, hale, grup, koleksiyon, bütün, tüm vücut, toplum, parça, kısım ve bölüm gibi anlamlara sahiptir. Bunlardan bazılarını sıralamak konunun daha iyi anlaşılması açısından önemlidir. Mandala sözcük olarak "daire", "çember" anlamlarına gelmektedir. Kaynaklarda doğu dillerine yapılan çevirilerde farklı şekillerde ifade edilmektedir. Nitekim bazı çevirilerde kimi zaman "merkez" kimi zaman "çevreleyen şey" manasında kullanıldığı görülmektedir. ${ }^{20}$ Mandala, bir kare içine çizilmiş, eşmerkezli ya da eşmerkezli olmayan dairelerden oluşan bir semboldür. ${ }^{21} \mathrm{Bu}$ sembol ya da semboller, dini uygulamalar esnasında kullanıldığ 1 gibi psikoloji ve rehabilitasyon alanlarında da kullanılmaktadır. Örneğin Budizm'de dini uygulamalarda meditasyon ve konsantrasyona yardım etmek için bir ritüel enstrümanı olarak karşımıza çıkmaktadır. Aynı şekilde psikoloji ve rehabilitasyon alanında ebeveynleri boşanan çocuklarda, nevroz ve şizofreni hastalarında tedavi ve rehabilite amaçlı kullanıldığı anlaşılmaktadır. Ayrıca birçok ekol tarafından halk hekimliği uygulamalarında mandala kullanımına

\footnotetext{
${ }^{18}$ Karataş, Nichiren Budizmi, s.125-126

${ }^{19}$ Lucia D. Dolce, "Criticism and Appropriation Nichiren's Attitude Toward Esoteric Buddhism”, (J.J.R.S.), C. XXVI, S. 3-4, s. 364.

${ }^{20}$ Mircea Eliade, Dinler Tarihine Giriş, (çev. Lale Arslan), Kabalcı Yay., İstanbul 2000, s. 360

${ }^{21}$ Eliade, Dinler Tarihine Giriş, s. 360.
} 
rastlanmaktadır. Özellikle tıbbi tedaviye cevap vermediği kabul edilen hastalarda tedavi amaçlı kullanıldığı görülmektedir. ${ }^{22}$ Mandala pek çok kültürde kutsal1, evreni, kozmik bilinci, kusursuzluğu ve varoluşun bütünlüğünü gösteren daire olarak tanımlanmaktadır. ${ }^{23}$ Bazı kaynaklarda mandala, "en yüksek noktaya sahip olmak", "her şeyin esasını bilmek" ve "en önemli parçaları birleştirmek" anlamlarına da gelmektedir. ${ }^{24}$

Mandalanın kelime anlamlarında biri diyagramdır. Mandalayı açıklamak için kullanılan bu ifade günümüzdeki en yaygın kullanımlar arasındadır. Nitekim bir bütünü ya da bir bütünün öğelerini, sıralı olayları ve olayların gelişim ve dönüşüm aşamalarını çeşitli grafiklerle veya farklı çizimlerle ifade ederken kullanılan diyagramlar, çok karmaşık olan durumları bazen şema ve işaretlerle anlaşılır k1labilmekte, daha kolay izah edilebilmesine ve zihnimizin daha rahat odaklanabilmesine olanak sağlamaktadır. ${ }^{25}$ Mandalalar bazı topluluklarca ikonik bir nesne olarak algilanmaktadır. Bafna; "On the Idea of the Mandala as a Governing Device in Indian Architectural Tradition" adlı çalışmasında mandalaların ikonik bir nesne olarak görülmesi eleştirmektedir. Bafna'ya göre mandalayı bir ikon olarak görmek yerine onu, üzerinde düşünülmesi gereken bir sembol olarak görmek daha doğru bir yaklaşımdır. Zira ona göre, mandala kullanmanın temel amaci; üzerinde odaklanılan ve düşünülen bir nesneyle bireyi kurtuluşa ulaştırmaktır. Bu bağlamda meditasyon esnasında özellikle yeni başlayanlar için kurtuluşa ulaşma noktasında mandalanın yardımcı olacağını da ileri sürmektedir. ${ }^{26}$

Mandala bireyin dinsel hayatını şekillendiren bir objedir. Mandala objeleriyle düşünsel olarak benlik duygusu yönlendirilmekte ve bilinçli kılınmaktadır. $\mathrm{Bu}$ anlamda mandala benliğe yön veren onu bilinçli kılan unsurlardan biridir. Mandala'nın en temel işlevi benliğin ilkel sezgileriyle dış evreni bir kılmak ve benliği bilinçlendirmektir. İnsan benliği üzerinde çok etkili olan bu semboller onun dini yaşantısında da bir araç haline gelmektedir. ${ }^{27}$

Mandala, özellikle eski Hint kültürünün etkisinde olan ülkelerde, çok eski kozmolojik kavramlara kadar dayanmaktadır. Bazı bilim insanları, Budizm

\footnotetext{
${ }^{22}$ Carl Gustav Jung, Mandala Symbolsm, Published By Princeton University Press, Usa 1973, S.3.

${ }^{23}$ Hewitt, Meditasyon (çev. Rezan Süer), s.86.

${ }^{24}$ Lucia D. Dolce, "Criticism and Appropriation Nichiren's Attitude Toward Esoteric Buddhism", s. 364.

${ }^{25}$ Karataş, Nichiren Budizmi, s. 125.

${ }^{26}$ Bafna, "On the Idea of the Mandala as a Governing Device in Indian Architectural Tradition", s.33.

${ }^{27}$ Victor N. Mansfield v. dğr., "Mandalas and Mesoamerican Pecked Circles", Current Anthropology, Vol. 22, s.270.
} 
öncesi Çin'deki mandala benzeri diyagramların da mandalalar ile benzerlikler gösterdiği ve her iki kullanımda da birçok ortak noktanın olabileceğine işaret etmektedirler. Onlarında tapınmak için kullanılan semboller ya da objeler olabileceğine kanıt bulmaya çalışmışlardır. $\mathrm{Bu}$ bağlamda daha önceki dönemlerde gelişmiş olan kozmogram fikrinin muhtemelen Mezopotamya zigguratından $^{28}$, antik Babil Kulesi'nden esinlenerek ortaya çıkmış olabileceği de düşünülmektedir. Ancak bu yapıları Hint formlarıyla ilişkilendiren doğrudan bir kanit yoktur. ${ }^{29}$

Yukarıda da ifade edildiği gibi mandalanın anlamı ve mandala kullanımlarının kavramsal çerçevesi oldukça geniştir. Dolayısıyla çok yönlü olan mandala konusu tantrik ve ezoterik anlayışlar ile bunların uygulamalar ekseninde Hint kökenli bazı dinlerle sınırlandırılmıştır. Konunun zorluklarından biri de ülkemizde daha önce böyle bir çalışmanın örneğine rastlanılmamış olmasıdır. Dolayısıyla mandalanın Hint kökenli bazı dini geleneklerdeki yeri ve önemi bu aşamadan sonra ortaya konulmaya çalışılacaktır.

\section{3- Hinduizm'de Mandala Anlayışı ve Geleneği}

Hinduizm'de mandala kullanımı tantrik metinlere dayandırılsa da varoluşunun ve ortaya çıkışının daha eski dönemlere kadar gittiği ve hatta Vedik döneme kadar uzandığ 1 (M.Ö. 1500 - 500) düşünülmektedir. Kaynaklarda mandalanın Hinduizm'de bir kavram olarak kullanımının Hint kutsal metin geleneğinin en önemli eserlerinden biri olan Rig Veda'ya dayandığ 1 ifade edilmektedir. Özellikle Mahabharata ${ }^{30}$ destanındaki kullanımda mandala ifadesinin genel metin içerisinde ana bölümleri ifade etmek için kullanıldığına dikkat çekilmektedir. Bu kullanımda aynı ya da yakın anlamlı epizotlar1 ${ }^{31}$, meseleleri, kişisel bilgi veya anlatımları gruplamak için kullanıldı̆̆ varsayılmaktadır. $\mathrm{Bu}$ bağlamdaki bir diğer iddia ise şu şekilde dile getirilmektedir. Hint kutsal metinlerinden Upanisad'ın çevirisinin sonunda mandala kelimesi; çevre, diyagram, daire, dairesel alan veya etrafı kare veya daire şeklinde sınırlanmış alan olarak tanımlanmaktadır. Ayrıca daire veya kare

\footnotetext{
${ }^{28}$ Ziggurat, Antik Mezopotamya vadisinde ve İran'da terası bulunan piramitlere benzeyen tapınak kulesidir. Zigguratlar eski Mezopotamya'da Sümerlerde, Babillerde ve Asurlarda bir çeşit tapınaktır. En eski ziggurat örnekleri basit yükselti platformları iken Ubaid döneminde MÖ 4000'li yillara aitti.

${ }^{29}$ Saunders, The Encyclopedia of Religion, s.155

${ }^{30}$ Mahabharata, Hindistan'ın iki büyük destanından biri. Dinsel içeriğinin yanı sıra yüksek edebi niteliğiyle de değer taşır.

${ }^{31}$ Epizot: Bir konuda ana olaydan ayrı olarak yer alan ve başlı başına konusal bir bütünlük gösteren olaylar, kişiler veya olgular.
} 
biçiminde yantralar içinde kullanılmaktadır. Yantra ${ }^{32}$ aslında metafizik olgularla alakalı bir durumdur. $\mathrm{Bu}$ ifade yaratılışın belirli olguları, güçleri, paralel dünyaları, çeşitli enerjiler ile resonansa girebilme imkânı sağlayan, güç katan, geometrik figürler içeren bir araçtır. Diğer bir deyişle Yantra varoluşun görülmez güçlerinin simetrisi ve geometrik tasviridir. ${ }^{33}$

Mandala mimariye rehberlik eden bir unsurdur. Hint mimari geleneğinde geçmişten günümüze kadar mandalanın etkisinin olduğu bilim adamlarınca ortaya konulmaktadır. Bu bağlamda Hint mimari geleneğinde mandala esas alınarak ortaya konulan yapıların ne anlama geldiği çok net ifade edilemese de özellikle kare 1zgara şeklinde çizilen Vastupurusa mandalanın ${ }^{34}$ dinsel anlamda mimariye rehberlik ettiği düşünülmektedir. Şehirler, binalar inşa edilirken Vastupurusa mandala çizgileri yönlendirici olmaktadır. ${ }^{35}$

Karmaşık bir geometrik tasarım olan mandala, Hinduizm'de evreni ritüel hareketlere dahil etmek için kullanılmaktadır. ${ }^{36}$ İlk Hindular'ın kozmolojik etkilere sahip geometrik tasarımlara olan ilgisi, Taittiriya Samhita ve Baudhayana Sulvasastra ile Apasthamba Sulvasastra Vedik sunaklarının inşasının dikkatlice incelenmesiyle kanıtlanmaktadır. $\mathrm{Bu}$ sunaklar içerisinde en çok bilinen Agnicayana ritüelinin şahin şeklindeki sunağıdır. Bu tasarımda öne çıkan hususlar, iyi tanımlanmış yerler ve ritüel sırasında tanrılara ayrılan koltuklardır. Diğer geometrik şekilli sunaklar üçgen, tekerlek vb. biçimlerde tasarlanmıştır. Bu sunakların hepsi, Caturasrasyenaciti, yani ateş sunağ 1 adı verilen kare desenler kullanılarak şahine benzetilen temel bir tasarımdan geliştirilmiştir. Bu bağlamda Hindu mandalalarında kullanılan birçok şekil ve düzlem, daha sonra ortaya çıktığı düşünülen mandalalara örneklik teşkil etmiştir. Nitekim sonraki mandalala örneklerindeki şekil, içerik ve tasarımların birçoğu tanrılar ve olağanüstü

\footnotetext{
${ }^{32}$ Yantra kelimesi Sanskritçe kökenli iki kelimenin birleşiminden doğmuştur. Yam ve Trana yani desteklemek ve özgürlük. Yantra Vedic ( Hint ) Astrolojisinde kullanılan, gezegenlerin negatif etkilerini dengelemek için kullanılan tılsımlardır. İki çeşit Yantra vardır. Sembolik bir diyagram olan resim yantra ve astrolojiye göre hesaplanan sihirli kare yantra. Her kişi için özel yantralar hazırlanabileceği gibi, günün özel yantrası da vardır.

${ }^{33}$ Saunders, The Encyclopedia of Religion, s. 156

${ }^{34}$ Vastupurusa Mandala: Göksel cisimlerin ve doğaüstü güçlerin akışını içeren bir binanın metafizik planıdır. Purusha enerji, güç, ruh veya kozmik adamı ifade eder. Mandala Sembolik olarak kozmosu temsil eden herhangi bir plan veya çizelgenin genel adıdır.

${ }^{35}$ Bafna, "On the Idea of the Mandala as a Governing Device in Indian Architectural Tradition", s. 26

${ }^{36}$ Saunders, The Encyclopedia of Religion, s.156
} 
varlıklarla kurulan ilişkiler ve bu ilişkilerde özel amaca yönelik talep ve sunum teknikleri dikkate alınarak geliştirilmiştir. ${ }^{37}$

Geometrik tasarımların ritüel amaçlar için başka bir açıklaması mimarlık el kitabı Vastusastras'ta bulunmaktadır. Hintli mimarlar tapınak inşasında başlangıç noktası olarak küçük ölçekli taslaklar yerine 81, 64 veya daha az kareden oluşan taslaklar kullanmışlardır. Böyle bir Vastumandala, çeşitli bölümlerinde ana tanrı, yardımcı tanrılar ve tapınak koruyucularının bulunduğu kozmik varlığın bedeni (Vastupurusa) olarak kabul edilmiştir. Vastumandala genellikle binanın gerçek tasarımı ile yakından bağlantılı olup tanrıların varlığını ifade etmektedir. ${ }^{38}$

Hinduizm'de günlük ve dolayısıyla daha özel ritüeller, Tantrik tüm mezheplerin ritüellerinde olduğu gibi, saf bir yüzey üzerinde vermilyon (parlak kırmızı) veya kırmızı sandal ağacı macunuyla oluşturulan geometrik tasarımların çizilmesiyle başlatılmaktadır. Bu diyagramlar ritüele başlayanlar için, kozmik bir güç kaynağı ve tanrının ritüel sırasında oturduğu yer manasına gelmektedir. $\mathrm{Bu}$ ritüellerde kullanılan bu diyagramlara da mandala denilmektedir. ${ }^{39}$

Hinduist mandala geleneğinde lotus çiçeği önemli bir sembol olarak karşımıza çıkmaktadır. Lotus çiçeğinin mandala objelerinde kullanımına çokça rastlanmaktadır. Bu bağlamda lotus aydınlanmayı ifade etmektedir. Hinduizm'de yaratıcı tanrı olarak kabul edilen Brahma'nın evreni yaratırken binyapraklı bir lotus çiçeğinin ortasında durduğuna inanılmakla birlikte lotus varlığın merkezine yerleştirilmektedir. ${ }^{40}$

Hinduizm'de lotus evrenle insan arasında bir köprü görevi görmektedir. Mandala objelerinde lotus çiçeğinin açması tanrısal güçlerin tezahürünü, dünyayı, aklı ve içgörüyü sembolize etmektedir. Bu noktada bir mandalanın merkezi lotustan yani tıpkı lotusun yapraklarının çiçeğin ortasından, yani göbeğinden çıkıp etrafa yayılmasından esinlenilerek oluşturulmuş ve merkeze bir tanrı figürü yerleştirilmiştir. Bu şekilde ilahi gücün merkezden dışa doğru yayıldığ 1 ifade edilmeye çalışılmıştır. ${ }^{41}$

Hint dinlerinde kullanılan mandalalarda başta aşkın varlık figürleri olmak üzere ana yönler, çeşitli unsurlar, maddi nesneler, manevi olgular ve psikolojik

\footnotetext{
${ }^{37}$ Peter Gaeffke, The Encyclopedia of Religion, Macmillann Publishing Company, Newyork 1987, Vol. 9, s.153

${ }^{38}$ Gaeffke, The Encyclopedia of Religion, s.154

${ }^{39}$ Gaeffke, The Encyclopedia of Religion, s.155

${ }^{40}$ Hewitt, Meditasyon, s.87.

${ }^{41}$ Brereton, The Encyclopedia of Religion, , s.28.
} 
yaklaşımlar gibi pek çok unsur dinlere ve uygulayan toplumlara göre değişmektedir. Bu çeşitlilik ve değişim daha çok Budizm'de; özellikle de Tibet Budizm'inde yaşanmaktadır. Mandalanın oluşturulmasında ve kullanılmasında şekil ve içerik açısında farklılıklar olsa da arketip, yani asıl şablon çoğu zaman aynidır. ${ }^{42}$

\section{4- Budizm'de Mandala Anlayışı ve Geleneği}

Mandala, Budist dini geleneklerinde tantrik unsurlarla ilişkilendirilerek kullanılan bir semboldür. Budizm'de mandala objeleri kullanılarak bireyin kurtuluşa ulaşması hedeflenmektedir. $\mathrm{Bu}$ bağlamda mandalanın Budizm içerisinde yaygın bir kullanım alanına sahip olduğu görülmektedir. ${ }^{43}$ Budizm'de, mandala başta meditasyon olmak üzere çoğu ritüelde kullanılan bir sembol olarak karşımıza çıkmaktadır. ${ }^{44}$

Budizm'de kullanılan mandala örneklerinde genellikle iki unsur ön plana çıkarılmaktadır. Budist dini geleneğinde bazı mandalalar sembol bazıları da temsil olarak kullanılmaktadır. Nadir de olsa her iki unsurun kullanıldığı mandala örnekleri de mevcuttur. Sembol olarak kullanılan mandalalar genelde herkes için hemen hemen aynı anlamı ifade ederken temsil şeklindeki mandalaların anlamı ve anlattığ mandalaların anlaşılması daha kolaydır. Temsil olarak kullanılan mandalaların anlaşılması zordur ve bir uygulayıcıya ya da bir yardımcıya ihtiyaç duyulmaktadır. Özellikle hem sembol hem de temsil olarak kullanılan mandalaların oluşturulması için seçilen figürler dini bir anlam ifade ediyorsa, kullanıcının da anlayabileceği düzeyde seçilmesi gerekir. ${ }^{45}$ Günümüzde bu tür mandala örnekleri giderek yaygınlaşmaktadır. Ancak ne kullanılan semboller ne de temsil için seçilen unsurlar konusunda kullanıcılara gerekli açıklamalar yapılmadığ1 gibi subliminal mesajlar verilmeye çalışıldığı düşünülmektedir.

Budist dini gelenekte mandala şemalarında genelde beş aşkın Budda'nın figürlerinin kullanıldığı görülmektedir. Mandalanın merkezinde Budda Vairocana (beyaz) ve ona bağlı olarak dört kozmik yöne yayılan Budda

\footnotetext{
42 Mansfield, Mandalas and Mesoamerican Pecked Circles", s.271.

${ }^{43}$ Bafna, "On the Idea of the Mandala as a Governing Device in Indian Architectural Tradition", s.32.

${ }^{44} \mathrm{https}$ ///studybuddhism.com/en/tibetan-buddhism/tantra/buddhist-tantra/"What is a mandala", 24.04.2019

${ }^{45} \mathrm{https} / / /$ studybuddhism.com/en/advanced-studies/vajrayana/tantra-theory/ "Explanation of mandalas their meaning and use", 24.04.2019
} 
Aksobhya (mavi), Budda Ratnasambhava (sarı), Budda Amitabha (kırmızı) ve Budda Amoghasiddhi (yeşil) yer almaktadır. ${ }^{46}$

Mandala çiziminde temel şemanın yanı sıra meditasyon esnasında bireysel farklı1ıklarda dikkate alınarak, bireyleri fiziksel, zihinsel ve duyuşsal anlamda uyaracak farklı semboller de kullanılabilmektedir. Bu semboller bitki ve hayvan figürlerinden müteşekkil biyolojik elementler, Budda figürleri ve süs eşyaları, silah, müzik aletleri gibi kültürel nesneler de olabilmektedir. Bu bağlamda çeşitli mandala sembollerinin kullanılmasının asıl nedeni meditasyon yapan kişiyi nihai amaca ulaştırmaktır. ${ }^{47}$

Budizm'de çok çeşitli mandala türleri vardır. Bunlar sutralarda ${ }^{48}$ ve tantaralarda birçok farklı amaç için kullanılmaktadır. Bunlardan birincisi "dış mandaladır”. Dış mandala dünyayı temsil eder. Temsil şeklindeki mandala türünden olduğu için de uygulayıcı bir öğreticiye ihtiyaç duymaktadır. İkinci mandala çeşidi ise kum mandalalardır. Bu mandalalar renkli kumlar kullanılarak iki boyutlu olarak tasarlanır. Üçüncü mandala türü ise zihinsel konsantrasyonu sağlayan mandalalardır. Bu mandala türü Tantrik ekollerin birçoğunda bulunur. ${ }^{49}$

Budizm günümüzde, dünyanın dört bir tarafına yayılmış hemen hemen her yerde taraftarı olan bir din olarak karşımıza çıkmaktadır. Budizm' in bu noktaya gelmesindeki etkenlerin başında misyonerlik faaliyetlerine önem vermesi gelmektedir. Bu durum Budizm içinde çeşitli ekollerin gelişmesine de zemin hazırlamıştır. Farklı ekoller temelde Budda'nın öğretisine sadık kalmakla birlikte ritüel ve uygulamalarda değişkenlik göstermişlerdir. ${ }^{50}$

\section{4-1. Çin ve Japon Budizmi’nde Manadala Anlayışı}

Budizm, Sakyamuni Budda ve ondan sonra müritleri tarafindan yürütülen çalışmalar neticesinde kurumsal kimliğini tamamlamıştır. Budda ve taraftarları bu yeni öğretiyi kurumsal bir din haline getirmeye ve yaymaya çalı̧̧ış olsalar da Kuzey Hindistan'nın Ganj vadisinde yerel bir inanç olan Budizm, Maurya Kralı Aşoka (M.Ö. 274-236), döneminde devletin ve dolayısıyla da bütün Hint coğrafyasının dini olmuştur. Bu dönemde gerçekleşen Pataliputra Konsilini takip

\footnotetext{
${ }^{46}$ Mansfield., "Mandalas and Mesoamerican Pecked Circles", s.271.

${ }^{47}$ Ter Ellingson, Evelyn Waugh, "Algebraic and Geometric Logic”, Philosophy East and West, University of Hawai'i Press 1974, Vol. 24, No. 1, s.29.

${ }^{48}$ Sutra: Budist kutsal metin külliyatının bir bölümüne verilen ad. Daha ziyade Mahayanistler tarafindan kabul edilen kutsal metinler olarak bilinir.

${ }^{49} \mathrm{https}: / /$ studybuddhism.com, "Explanation of mandalas their meaning and use", 24.04.2019

${ }^{50}$ Yitik, "Budizm”, s.362.
} 
eden süreç, Budizm'in ülke dışına yayılmaya başlamasını sağlamıştır. ${ }^{51}$ Budizm önce Hindista'nın güneyindeki coğrafyada ardından da tarihi ipek yolu vasıtasıyla Kuzey bölgelerde yayılmıştır. Nitekim Mahayana ekolünün etki edeceği Kuzey Budizmi ilk etapta Hindistandan Çin'e; oradan da diğer uzak doğu topluluklarına ulaşmıştır. Budizm yayılma sürecinde değişimlere de uğramıştır. Bu noktada hem Budizm hem de Budizm'in yayıldığı toplumlarda değişim ve etkileşim karşılıklı olmuştur. ${ }^{52}$

Miladi birinci yüzyılda Budizm'le tanışan Çin'de ezoterik uygulamalar ve mandala kullanımı üçüncü yüzyılla sekizinci yüzyıl arasında gelişim göstermiştir. Ezoterik uygulamalar diğer Budist geleneklerde olduğu gibi Çin Budizmi’ne de Mahayana'nın etkisiyle girmiştir. Bu dönemde mandala ve mantra kullanımı Çin Budizmi'ne Mahayanist kutsal metinler vasıtasıyla etki etmiştir. Kullanılan mandalalar arasında Sakyamuni Budda figürlü mandalalar daha çok yer almış; dokuzuncu yüzyıldan sonra da mandala kullanımı artarak devam etmiştir. ${ }^{53}$

Çin, Budizm'le tanışıp onu kabullendikten sonra miladi altıncı yüzyılın ortalarında bu dini Japonya'ya ihraç etmeye başlamıştır. Budizm'in Hindistan'da başlayan yolculuğu bu vesileyle Japonya'ya kadar ulaşmıştır. Japon Budizmi'nin temelleri Çin Budizmi'nden aldıkları öğretiler üzerine atılmıştır. Bu bağlamda Japon din adamları Çin'e gidip orada Budizm'i, Budist ritüel ve uygulamaları öğrenip Japonya'ya taşımışlardır. ${ }^{54}$

Japon Budizmi'nin Çin Budizmi'nin üzerine inşa edilmesi Mahayana ekolünün ezoterik ve tantrik uygulamaların da Japon Budizmi'nde yer bulmasını sağlamıştır. Bu noktada Çin'de Mahayana ekolünün etkisiyle gelişen Budizm Japonya'da da aynı doğrultuda gelişmiştir. Nitekim başta meditasyon olmak üzere çoğu ritüelde kullanılan mandala objeleri de Japon Budizmi’nde kendine yer bulmuştur. ${ }^{55}$

Mandala geleneğinin Japon Budizmi'nde yer bulmasında Kukai'nin çok büyük katkısı olmuştur. Miladi 774 yılında Japonya'nın Kotohiro şehrinde dünyaya gelen Kukai yirmili yaşlara geldiğinde Budizm'i ve Budizm'in ezoterik

\footnotetext{
${ }^{51}$ Hüsamettin Karataş, "Sakyamuni Buda'nın Tarihsel Kişiliği ve Öğretisinin Yeni Bir Din Haline Geliş Süreci”, Dini Araştırmalar Dergisi, C.16. S.42, s. 135-137.

${ }^{52}$ Hammet Arslan, "Budizm'in Çin'e Girişinde İpek Yolunun Önemi ve İşlevi”, Çukurova Üniversitesi İlahiyat Fakültesi Dergisi, C.18, S.1, s.8.

53 Alex Wayman, "Buddhism, Schools Of: Tantric Ritual Schools Of Buddhism [First Edition]”, Encyclopedia Of Religion, C.2., s.1214.

${ }^{54}$ Vedat Şafak Yam1, Japonya'da Budizm, Ankara 2012, s.19,20.

${ }^{55}$ Yam1, Japonya'da Budizm, s.46.
} 
uygulamalarını öğrenmek için yaklaşık iki buçuk yıl Çin'de kalmıştır. ${ }^{56} \mathrm{Bu}$ süre içerisinde Budist dini metinleri Çinli Budist rahiplerden öğrenmiş olan Kukai Japonya'ya Budist kutsal metin literatürünün yanı sıra beş adet mandala tablosuyla birlikte dönmüştür. ${ }^{57}$

Japon Budizmi'nde Kukai ile başlayan mandara ${ }^{58}$ geleneğinin kullanımı tarihsel süreç içerisinde gelişerek devam etmiştir. Mandaranın Japon Budizm'i içerisindeki tarihsel gelişiminde Japon Budizmi'nin bir kolu olan Nichiren Budizm'i önemli bir mihenk taş1 olmuştur. Nichiren Budizmi'nde mandara anlayışı, genel olarak honzon-shu öğretileri içinde ifadesini bulmuş ve bu inancın dışa yansıyan yönünü temsil etmiştir. Nichiren Budizmi'nde mandaralar, esoterik ve tantrik eğilimli dini gruplarda olduğu gibi, meditasyon yapmak, dua etmek ve tapınmak için kullanılmıştır. ${ }^{59}$ Bu maksatla Nichiren tarafından çeşitli özellikleri ön plana çıkarılmış olan bazı mandara veya dua çarkı örnekleri oluşturulmuştur. ${ }^{60}$

Nichiren Budizmi'nin temelinde yer alan honzon-shu öğretisi, mandaraların şekil ve içeriğinin belirlenmesinde önemli bir rol üstlenmiştir. Bu bağlamda Nichiren, inanılmasını gerekli gördügü bütün yüce olguları ve bu olguların özünde saklı olduğunu düşündüğü bütün gizemli fikirleri, kendine has bir şekilde düzenlemiş, bunları sistemli olarak mandaralarına yerleştirmiştir. O, bunun için yazı ve şekillerin yer aldığı şematik tablolar hazırlamış ve bunları sembollerle ifade ederek somut hale getirmiştir. ${ }^{61}$ Nichiren, kaleme aldığ bazı metinlerde hazırlamış olduğu mandaraların içeriğinden bahsetmiş, bunun yanı sıra onları nasıl şematik hale getirdiğini ve tablolara ne şekilde yerleştirdiğini açıklamıştır. ${ }^{62}$ Nichiren, özellikle Sado Adasında sürgünde olduğu yıllarda bu konuya ağırlık vermiş, 1273 yılında yazdığı "kanjinhonzonshu" başlıklı yazısıyla bu meseleyi etraflıca izah etmeye çalışmıştır. ${ }^{63} \mathrm{O}$, "kanjinhonzonshu" yazısı ile mandaraların hem teorik yönünü hem de pratik yönünü ortaya koymuş, inanç ve ibadetle alakalı bazı konuları ise honzon-shu öğreti etrafında şekillendirmiştir. ${ }^{64}$

\footnotetext{
${ }^{56}$ Barbara Morrison, "Kukai's Innovations and Efforts in Introducing Vajrayâna Buddhism in Japan", Mandala of 21st Century Perspectives, Centre for Bhutan Studies yay., Bhutan 2017, s.196. 57 Yam1, Japonya'da Budizm, s.176.

${ }^{58}$ Mandala kavramı yerine Japon Budizmi’nde mandara sözcüğü kullanılmıştır. Bundan dolayı Japon Budizmi'nde mandala geleneğinden bahsederken mandara sözcüğü kullanılacaktır.

${ }^{59}$ Dolce, "Criticism and Appropriation Nichiren's Attitude Toward Esoteric Buddhism", s. 355.

${ }^{60}$ Petzold, Buddhist Prophet Nichiren - A Lotus in The Sun, s. 25.

${ }^{61}$ Dolce, "Criticism and Appropriation Nichiren's Attitude Toward Esotric Buddhism", s. 364.

${ }^{62}$ Writings of Nichiren Shonin, C. II, s. 168.

${ }^{63}$ The Writings of Nichiren Daishonin, C. II, s. 415.

${ }^{64}$ Dolce, "Criticism and Appropriation Nichiren's Attitude Toward Esoteric Buddhism", s. 365; Writings of Nichiren Shonin, C. II, s. 169.
} 
Nichirenci gruplar arasında, mandaraların sayısı başta olmak üzere bunların hangi unsurlardan meydana geldiği, mandaralarda yer alan öğelerin ne şekilde ifade edildiği ve hangi sisteme göre yerleştirildiği konusu tartış1lmış, bununla birlikte söz konusu olan mandaraların büyük çoğunluğunun Nichiren tarafindan oluşturulduğu kabul görmüştür. Çeşitli kaynaklarda Nichiren'in yirmi sekiz ila yüz arasında değişen sayıdaki mandarayı hazırladığı ifade edilmiştir. ${ }^{65}$

\section{4-2. Tibet Budizmi'nde Mandala Anlayısıı}

Budizm'de mandala geleneğinin en görkemli şekli Tibet Budizmi'nde görülmektedir. Tibet Budizm'i mandala sembolizminin detaylandırılması, işlev ve anlam bakımından zenginleştirilmesi açısından dikkat çekmektedir. ${ }^{66}$ Tibet mandalaları barok ${ }^{67}$ üslubu, görkemli desenleri ve parlak renkleriyle kudretli ve zengin bir sembolizm oluştururlar. Ayrıca Tibet mandalaları tasarımlarıyla değerli birer sanat eseri konumundadır. Mandalalarda kullanılan renkler meditatörün psikolojisini etkileyecek şekilde seçilmiştir. ${ }^{68}$

Tibet Budizmi tantrik ve ezoterik dini uygulamaların baskın bir şekilde kullanıldığı bir Budist ekoldür. Tantrizmin ve uygulamalarının Tibet'e girişinde ve gelişiminde Tibetlilerin kötü ruhlarla ve şeytanla mücadelelerinin önemli rol oynadığ1 görülmektedir. Tibet'in bu yönünü iyi tahlil etmiş olan Budist misyonerlerin sayesinde tantrizm ve uygulamalarının Tibet'e girip gelişim gösterdiği bilinmektedir. Tantrizmin ve ezoterizmin gizli yönleri, gizli güçleri ve derin bilinç oluşturma özelliği Tibetliler tarafından ilgiyle karşılanmıştır. ${ }^{69}$

Mandala objelerinde daha önce de değinildiği üzere temelde Budda figürlerinin kullanılması yaygın bir durumdur. Ancak Tibet Budizm'inde bu yaygın kullanıma ilaveten beş Budda ${ }^{70}$ figürünün yanı sıra kadın figürlere de yer verilmektedir. ${ }^{71} \mathrm{Bu}$ durum Guhyagarbha Tantra' da şu şekilde ifade edilmektedir: "O zaman Büyük Sevinçli Bhagavan, vajrayı ellerine vermiş, adın başlangıcını

\footnotetext{
${ }^{65}$ Living Buddhism, Soka Gakkai Publigations-World Tribune, USA 1997, s. 13-17.

${ }^{66}$ Mansfield , "Mandalas and Mesoamerican Pecked Circles", s.271.

${ }^{67}$ Avrupa'da XVI. yüzyılın sonlarında başlayıp XVIII. yüzyılın ortalarına değin süren, güzel sanatlarda şaşırtmayı, görkemi ve göz kamaştırıcıllğı yeğleyen bir sanat biçimi; özellikle mimaride, plastik sanatlarda, müzikte bu biçimle büyük yapıtlar ortaya konmuştur.

${ }^{68}$ Hewitt, Meditasyon, s.87.

${ }^{69}$ Jacob Dalton, "The Early Development of the Padmasambhava Legend in Tibet: A Study of IOL Tib J 644and Pelliot Tibétain 307", Journal of the American Oriental Society, Vol. 124, No. 4, 2004, s.760.

${ }^{70}$ Genelde mandala objelerinde kullanılan beş aşkın Budda'nın isimleri şöyledir: Akshobhya Buddha, Amitabha Buddha, Amoghasiddhi Buddha, Ratnasambhava Buddha, Vairocana Buddha.

${ }^{71}$ Mansfield , "Mandalas and Mesoamerican Pecked Circles", s.271.
} 
vermiş, sonra onları mandalaların diş kenarlarına yerleştirmiştir." 72 Mandala içeriği olarak diğer Budist ekollerde olduğu gibi bireysel anlayış ve kavrayış düzeyi de dikkate alınarak çeşitli figürlerin kullanıldığı mandalalar da üretilmektedir. Bu semboller bitki ve hayvan figürlerinden müteşekkil biyolojik elementler, Budda figürleri ve süs eşyaları, silah, müzik aletleri gibi kültürel nesneler de olabilmektedir. Bu bağlamda çeşitli mandala sembollerinin kullanılmasının nedeni meditasyon yapan kişiyi nihai amaç olan Nirvanaya ulaştırmaktır. $^{73}$

Tibet mandalalarının çiziminde geometrik mantığın çok iyi bir şekilde kullanıldığı görülmektedir. Mandala, Tibet tantrik dini geleneğinde geometrik yapılar içerisine çizilmiş resimli semboller olarak ortaya konulmaktadır. Tibet Budizmi'nde mandalanın temel şekli, köşegenleri ve çapları olan ve bir kareyi çevreleyen bir çember şeklinde görülmektedir. ${ }^{74} \mathrm{Bu}$ noktada genelde dört üçgene bölünmüş bir kareyi çevreleyen bir veya daha fazla eşmerkezli daireyi içeren oldukça karmaşık bir tasarım karşımıza çıkmaktadır. Ayrıca mandalalar eşzamanlı olarak bir kozmogramı, bir psikogramı ve dini güçlerin elde edilebileceği saflaştırılmış bir ritüel bölgesini temsil ettikleri için her üçgenin merkezinde de, kutsal figürlerin görüntülerini veya amblemlerini içeren semboller kullanılmaktadır. ${ }^{75}$

Tibet mandalalarında kullanılan daire ve kare geometrik öğelerinin çeşitli anlamları bulunmaktadır. Çember samsara döngüsünü, dünyadaki varoluş ve doğumları temsil etmektedir. Aynı zamanda çember şekli, içindeki yapısal sistemin özel karakteristiğini tanımlayan bir sınırdır. Dış halkası, yanılsamaları gideren aydınlanma ateşini, ortası ise pırlanta gibi netliği açıklığı ifade etmektedir. Tibet Budizmi'nde ki kare mandala formları ise oldukça düzenli bir yapı teşkil etmektedir. Görsel olarak duvarlarına mücevherler asılmış tepesinde kraliyet şemsiyeleri olan bir sarayı andırmaktadır. Kare formlarda at ve tek boynuzlu geyik figürleri de kullanılmaktadır. Aynı zamanda kare formlar mantıksal olarak, benzerlik ve denklik ilişkilerini ön plana çıkaran sembollerin yerleştirilebileceği yapılar olarak görülmektedir. ${ }^{76}$

\footnotetext{
${ }^{72}$ Guhyagarbha Tantra, 206.1

${ }^{73}$ Ter Ellingson, Evelyn Waugh, "Algebraic and Geometric Logic", s.29.

${ }^{74}$ Ter Ellingson, Evelyn Waugh, "Algebraic and Geometric Logic", s.26.

${ }^{75}$ Mircea Eliade, Yoga, Princeton University Press, New Jersey 2009, s.219.

76 Ter Ellingson, Evelyn Waugh, “Algebraic and Geometric Logic”, s.26.
} 


\section{SONUÇ VE DEĞERLENDIRME}

Mandala, üzerinde odaklanılarak zihinsel olarak bireyi aşkın ve yüce varlıkla bir kılıp kurtuluşa ulaştırmayı hedefleyen, geometrik olarak farklı desenlere sahip olan ve içerikleri de değişkenlik gösteren obje veya sembol olarak tanımlanmaktadır. Mandala genel olarak yoga ve meditasyon sirasinda kullanılmaktadır.

Hint kökenli dinlerde, özelliklede tantrik ve ezoterik dini gruplarda bir ritüel olarak kullanılan mandalanın geçmişi çok eskilere dayanmaktadır. Hinduizm'de mandala kullanımı tantrik metinlere dayandırılsa da varoluşunun ve ortaya çıkışının daha eski dönemlere kadar gittiği Vedik döneme kadar uzandığı (M.Ö. 1500 - 500) düşünülmektedir. Mandalanın kavramsal olarak ortaya çıkması Hint kutsal metin geleneğinin en önemli eserlerinden biri olan Rig Veda'ya dayandığı ifade edilmektedir. Bu anlamda mandala kavramının genel metin içerisindeki ana bölümleri ifade etmek için kullanıldığ 1 bilinmektedir.

Hinduizm ve Budizm'de mandalanın kendisine geniş bir şekilde yer bulduğu görülmektedir. Örneğin mandalalar Hint mimarisine yön veren bir unsur olarak karşımıza çıkmaktadır. Bu anlamda Vastupurusa Mandala Hint mimarisinde yönlendirici bir unsur olmuştur. Hintlilerin kozmolojiye olan ilgisi de mandala kullanımına yansıyan unsurlardandır. Bu bağlamda Hindular evreni ritüel hareketlere dahil etmek için mandala objelerini kullanmışlardır.

Budizm'de de mandala kullanımı Hinduizm'deki gibi yaygın bir alana sahiptir. Mandala, Budist dini geleneklerinde tantrik unsurlarla ilişkilendirilerek kullanılan bir sembol olarak karşımıza çıkmaktadır. Budizm'de mandala objeleri kullanılarak bireyin kurtuluşa ulaşması hedeflenmektedir. Budizm'de çok çeşitli mandala türleri vardır, bunlar sutralarda ve tantaralarda birçok farklı amaç için kullanılmaktadır. Budist dini gelenekte mandala şemalarında genelde beş aşkın Budda'nın figürlerinin kullanıldığı görülmektedir. Bu temel mandala şemasının yanı sıra meditasyon esnasında bireysel farklılıklarda dikkate alınarak, bireyleri fiziksel, zihinsel ve duyuşsal anlamda uyaracak farklı semboller de kullanılabilmektedir.

Budistlerin ezoterik öğretiler çerçevesinde inanç ve ibadet amaçlı oluşturdukları mandalalar genellikle daire, kare veya dikey dikdörtgen biçimlidir. Elbette zamanın şartlarına, bölgenin ekonomik özelliklerine ve teknik açıdan kullanılacak malzemelere göre de değişiklikler olmuştur. Bu durumda mandala yapılırken taş, toprak, mermer, deri, kumaş, tahta veya kâğıt malzemeler de kullanılmıştır. Bu türden gereçlerin üzerine kendi içinde uyumlu ve anlamlı olan şekiller çizilmiş ve çok çeşitli mandalalar oluşturulmuştur. $\mathrm{Bu}$ bağlamda 
Ezoterik öğretilere dayalı tamamlayıcı temsiller öngören çeşitli mandala türlerini içeriği hakkında şunları söylemek/sıralamak mümkündür;

1- Kutsal yazıların (kitaplara, eserlere, metinlere dayalı) merkeze alındığı mandalalar.

2- Kutsalın özüne veya asıl niteliklerine dayalı mandalalar.

3- Kutsal kabul edilen heykel veya tanrısal büstlerin merkeze alındığı mandalalar.

4- Harf veya şekilsel sembollerin merkeze alındığı mandalalar.

Yukarıda kısaca izah etmeye çalıştı̆̆ımız mandala türleri ve içerikleri gruptan gruba farklılık gösterebilmektedir. Nitekim mandalalarda kullanılan harfler, kelimeler ve şekilsel unsurlar kendi içinde özel anlam taşıyacak biçimde yansıtılmış simgesel ifadelerdir. Ayrıca mandalalarda yer alan her öğenin ayrı bir mistik yönünün olduğuna, bunların mucizevî bir olguyu yansıttığına ve tüm yönleriyle temsil ettiğine inanılmıştır.

Tantrik ve ezoterik gruplarda kullanılan mandalalar hazırlanış biçimi ve içerik olarak birbirlerinden farklıdır. Bu tür mandalaların içeriği bazen daha kapsamlı olurken bazen de çeşitli kısaltmalar kullanılarak farklı tipte ve daha küçük biçimde yapılabilmektedir. Zira dönemin şartları ve insanların beklentilerinin de bu duruma etki ettiğini kolaylıkla söyleyebiliriz. Ayrıca mandalayı hazırlayan kişinin ya da grubun değer yargıları yanında halkın kabulünü kolaylaştıracak bazı kültürel unsurları da mandalalara yansıttıkları görülmektedir. Bu durum ise mandaların sayısının ve çeşidinin artmasına vesile olmuştur.

Tantrik ve ezoterik mandalalarda yer verilen ve bir şekille sembol değer haline getirilen her öğe, sadece bütünün herhangi bir parçası olarak değil, tek başına da değerli kabul edilmiş̧ir. Buna göre mandalalarda yer bulan unsurlar, zaman zaman tek başlarına ön plana çıkarılmış olsalar da kendi içlerinde hiyerarşik bir sıralamaya tabi tutulmuşlardır. Söz konusu hiyerarşik değer onların yüklendikleri kutsallık veya kutsallarla olan ilişkilerindeki konumlarından kaynaklanmıştır. Mandalaların içeriğinde var olan hiyerarşik değer, onun özüne yerleştirildiğine inanılan öğretilerinin dışa yansıması olarak görülmüş ve bu mandalalar saygı duyulan ve tapınılan objeler haline getirilmiştir.

\section{KAYNAKÇA / REFERENCES}

Anesaki, M. (1916). Nichiren The Buddhist Prophet. Cambridge. 
Arslan, H. (2018). Budizm'in Çin'e Girişinde İpek Yolunun Önemi ve İşlevi. Çukurova Üniversitesi İlahiyat Fakültesi Dergisi, 18(1), 1-21.

Bafna, S. (2000). On the Idea of the Mandala as a Governing Device in Indian Architectural Tradition. Journal of the Society of Architectural Historians, 59(1).

Blofeld, J. (1992). The Tantric Mysticism of Tibet. Penguin Group Published, Arkana.

Brereton, J. P. (1987). The Encyclopedia of Religion. Macmillann Publishing Company, Newyork.

Dalton, J. (2004). The Early Development of the Padmasambhava Legend in Tibet: A Study of IOL.

Tib, J. 644 \& Pelliot Tibétain 307. Journal of the American Oriental Society, 124(4).

Chawdhri, L. R. (1985). Practicals of Mantras and Tantras. Sagar Publication, New Delhi. Dictionary of Buddhism, Published by Soka Gakkai, Tokyo.

Dolce, L. D. (1999). Criticism and Appropriation Nichiren's Attitude Toward Esoteric Buddhism. Japanese Journal Religious Studies, XXVI(3), 3-4.

Eliade, M. (2015). Dinler Tarihine Giriş (Çev. Lale Arslan). Kabalcı Yay., İstanbul.

Eliade, M. (2009). Yoga. Princeton University Press, New Jersey.

Ellingson, T. \& Waugh E. (1974). Algebraic and Geometric Logic. Philosophy East and West, University of Hawai'i Press.

Gaeffke, P. (1987). The Encyclopedia of Religion. Macmillann Publishing Company, Newyork

Hewitt, J. (1988). Meditasyon (Çev. Rezan Süer). Akaşa yay., İstanbul.

Jung, C. G. (1972). Mandala Symbolism. Translated by R.F.C. Hull, Published By Princeton University Press, USA.

Karataş, H. (2012). Nichiren Budizmi. Ankara Üniversitesi Sosyal Bilimler Enstitüsü, Basılmamış Doktora Tezi, Ankara.

Karataş, H. (2013). Sakyamuni Buda'nın Tarihsel Kişiliği ve Öğretisinin Yeni Bir Din Haline Geliş Süreci. Dini Araştırmalar Dergisi, 16(42).

Living Buddhism (1997). Soka Gakkai Publigations-World Tribune, USA. 


\section{Hüsamettin KARATAŞ}

Mansfield, V. (1981). Mandalas and Mesoamerican Pecked Circles. Current Anthropology, 22.

Morrison, B. (2017). Kukai's Innovations and Efforts in Introducing Vajrayâna Buddhism in Japan. Centre for Bhutan Studies yay., Bhutan.

Petzold, B. (1978). Buddhist Prophet Nichiren: A Lotus in The Sun. Tokyo.

Saunders, E. D. (1987). The Encyclopedia of Religion. Macmillann Publishing Company, Newyork

The Writings of Nichiren Daishonin (2006). Editor-Translator: The Gosho Translation Committee, Published by Soka Gakkai, C.II, Tokyo.

Wayman, A. (1987). Buddhısm, Schools of Tantrıc Ritual Schools of Buddhism. Encyclopedia of Religion, 2.

Wirtings of Nichiren Shonin (1996). Edited by George Tanabe, Compiled by Kyotsu Hori, II. Tokyo

Yami, V. Ş. (2012). Japonya'da Budizm. Doğu Batı Yayınları, Ankara.

Yitik, A. İ. (2014). Doğu Dinleri. İSAM Yayınları, Ankara.

Yitik, A. İ. (1996). Hint Kökenli Dinlerde Karma Inancının Tenasüh İnancıyla Illişkisi. Ruh ve Madde Yayınları, İstanbul. 